Research Article

\title{
Evaluation of Backfill Operation Models Using SBSC and IFAHP Approach
}

\author{
Yan Li (iD \\ School of Business, Xi'an University of Finance and Economics, Xi'an 710100, China \\ Correspondence should be addressed to Yan Li; liyan@xaufe.edu.cn
}

Received 31 December 2020; Revised 28 March 2021; Accepted 10 April 2021; Published 23 April 2021

Academic Editor: Qianqian Wang

Copyright (c) 2021 Yan Li. This is an open access article distributed under the Creative Commons Attribution License, which permits unrestricted use, distribution, and reproduction in any medium, provided the original work is properly cited.

\begin{abstract}
As the mine backfill is recognized as one promising technique for the sustainable development, it is crucial to explore the backfill operation mechanism for the mining industry. At present, the self-management and outsourcing model are generally selected to apply in backfill operation and management worldwide. The advantages are insufficient from the strategic and sustainable perspective. Therefore, the study proposes joint venture alliance and concerns the superiority on mine backfill management. In order to evaluate the models, this study puts forward the integrated method which involves combination of SBSC and IFAHP. A strategic and hierarchical framework of SBSC on the basis of sustainability is formulated, which includes 6 perspectives and 16 secondary indexes. Simultaneously, the IFAHP approach is used for determination of the weights of indexes and calculation of the final score, which enables to assess mine backfill operation activity more objectively. The results show that the self-management model provides little advantages whereas the outsourcing model is the better operation mechanism. By contrast, joint venture alliance is rated as the optimal backfill operation model of the mining industry. The research findings of this study would help the mining industry to evaluate objectively and make an appropriate decision on the backfill operation model in the mining industry.
\end{abstract}

\section{Introduction}

Mine backfill has been widely used worldwide. The building process of the backfill station was associated with several steps including feasibility analysis, design, procurement, construction, installation, and debugging; the backfill operating process did not begin until the employees finished training of professional skills (as shown in Figure 1). For the management of the backfill station, some countries such as Chile and South America adopted the traditional selfmanagement model. Therefore, the mining industries need to spend several years and much energy on the preparation activity before conducting the operational process of the backfill station.

Some countries proposed the outsourcing model, which has been practiced in business management in various fields ranging from IT/IS to logistics [1]. Some mining industries have outsourced noncore business activity to the private partner or service provider, even recently the scope of outsourcing expanded to certain core business [2]. There are instances like South Africa and Canada where the backfill project was outsourced to service providers with expertise. The reasons for outsourcing are acquisition of specialized competencies, good flexibility in adapting to the environment and geology, and reduction of cost mainly including fixed assets [3]. Moreover, outsourcing is conducive to strategic enhancement of industry core competencies [4]. However, there were reports from Indian coal mining industries which showed unsatisfactory conclusions with respect to outsourcing by empirical evidence $[5,6]$. In addition, there may be other deficiencies including increase in extra cost and disclosure of confidential information [7]. Moreover, the top risk of outsourcing is that the quality of the product or service is not fully controlled [3].

At present, the mining industries dominantly adopt selfmanagement or outsourcing as the backfill operation model worldwide. In China, the mining industries generally select the self-management model. However, joint venture alliance was still under-appreciated in terms of backfill operation mechanism and was rarely used. Joint venture alliance 


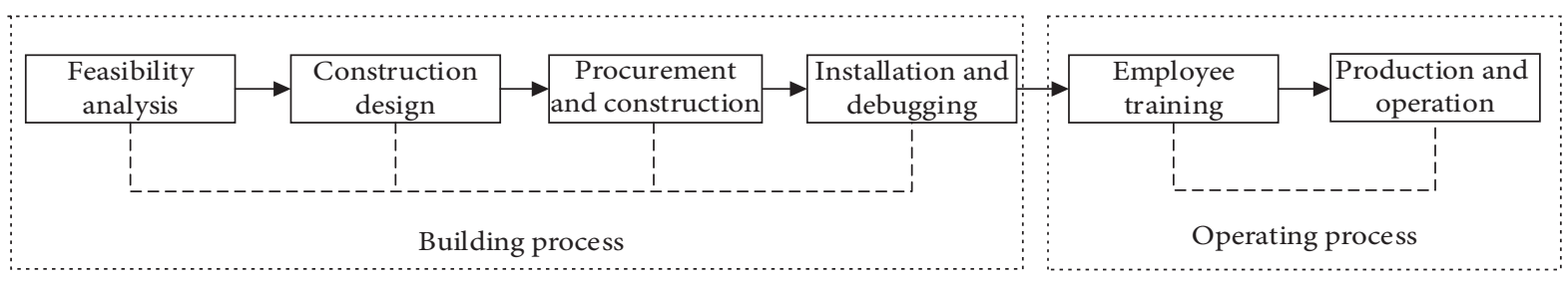

FIGURE 1: Building and operating process of mine backfill.

provided access to special technology and skill from alliance partners [8]. Generally, the industries need to select the alliance partner with complementary resource such as market, expertise, and capital investment [9]. Furthermore, joint venture alliance highlighted long-term reciprocal commitment and mutual trust so that competitive advantage of alliance was reinforced. Nevertheless, joint venture alliance was yet unsatisfactory, and there may exist some risks including selection of alliance partner, poor flexibility, and constraint of the government policy $[10,11]$.

The inefficient management model is unfavorable for the development of mine backfill; therefore, it is crucial to make decision on selecting the appropriate backfill operation model. Multicriteria decision-making (MCDM) technology contributes to assess and determine the best alternative in the case of conflicting criteria and objectives. There have been some studies on exploring decision-making by MCDM including Analytic Hierarchy Process (AHP) [12], Analytical Network Process (ANP) [13], PROMETHEE [14], DecisionMaking Trial and Evaluation Laboratory (DEMATEL) [15], Technique for Order Preference by Similarity to Ideal Solution (TOPSIS) [16], Data Envelopment Analysis (DEA) [17], Vlse Kriterijumska Optimizacija Kompromisno Resenje (VIKOR) [18], linear programming, and hybrid approach such as fuzzy AHP [19]. MCDM techniques are classified as individual and hybrid methods, of which AHP, RPOMETHEE, ELECTRE, TOPSIS, ANP, and VIKOR are considered as the most frequent applications in energy decision [20]. Fuzzy MCDM has been widely used since fuzzy sets are conducive to tackling uncertainties and vagueness, from which intuitionistic fuzzy decision-making was developed. Xue (2021) applied the intuitionistic fuzzy set to explore the database retrieval and decision-making based on the uncertain database [21]. Garg (2020) developed the fuzzy set and addressed the complex interval-valued q-rung orthopair fuzzy set (IVq-ROFS) to deal with uncertain information in the decision-making process [22]. Puri (2017) concerned a new set of weights methodology for multicomponent data envelopment analysis (MC-DEA) with uncertain data to measure interval efficiencies, which has been applied to banks in India [23]. Moreover, researchers tend to utilize integrated MCDM involving two or more methods to find optimal results. Sustainable balanced scorecard (SBSC) is a tool to build the concept framework on the basis of sustainability for more efficient operation of the organization [24]. There was no literature that integrate SBSC with intuitionistic fuzzy AHP (IFAHP) for performance evaluation. In order to select the optimal model among self-management, outsourcing, and proposed joint venture alliance, the study attempts to establish the conceptual framework for evaluation of backfill operation. Moreover, the study tries to adopt the hybrid MCDM methods combing SBSC with IFAHP to make the optimal and appropriate decision for mine backfill industries.

\section{Review of Literature}

2.1. SBSC. SBSC was developed on the basis of BSC, which was proposed by Professor Kaplan and Norton for the first time [25]. BSC broke through traditional evaluation criteria viewing only financial indexes as a measure of organizational performance and took the nonfinancial issue into account; therefore, a balanced and strategic framework with the financial factor and nonfinancial factor was formulated, which covered four perspectives including financial, customers, internal operations, learning, and growth.

However, the BSC method focused only on the internal management of organization, but ignored the surroundings in which the organization was admitted to keep sustainable development. Figge (2002) expressed the process of social and environmental impact on business activities and incorporated social and environmental issues into the strategic framework of SBSC; correspondingly, nonmarket became the fifth perspective [26]. Sidiropoulos (2004) supported sustainable indexes into operational performance [27]. Möller and Schaltegger (2005) embedded eco-efficiency indexes into sustainable performance measure [28]. Hubbard (2009) proposed that the organization should be responsible for stakeholders and modified the SBSC framework structure lying in stakeholders' perspective [29]. Tsalis (2013) addressed the SBSC approach that contributed to enhance social responsibility awareness of the industry [30]. As a result, both the eco-efficiency element and sustainability element were integrated into the hierarchical evaluation system of SBSC in which economic, environmental, and social factors were combined. Simultaneously, the environmental and social perspective help stimulate growth of the value added $[31,32]$.

2.2. IFAHP. IFAHP is a comprehensive evaluation method formulated by combining intuitionistic fuzzy sets and AHP. The AHP method was employed to quantify experience and subjective judgment of experts, which was proposed by Saaty [33]. Although a noticeable advantage of AHP was that the method enables to transform qualitative analysis into the quantitative issue, and expert judgment with ambiguity has not been considered. Therefore, the degree of membership 
derived from fuzzy mathematics was introduced to the AHP approach. However, this method cannot provide a quantitative description of hesitation and abstention, and the subjectivity of the evaluation remains strong. The intuitionistic fuzzy set was further integrated to AHP, in which the hesitancy degree enables to show the hesitation situation in the evaluation process. IFAHP was developed by Xu and Liao, which covers the degree of membership, the degree of nonmembership, and hesitancy degree [34]. With respect to IFAHP, there are several extremely significant advantages. Since the hesitancy degree may explain the hesitation of experts, the IFAHP approach can effectively solve the subjectivity of expert decision-making in the evaluation process. Moreover, the weights of indexes are obtained by experts scoring, while its consistency test fails, the correction is fulfilled by adjusting the iterative parameters, so there is no need to gather experts for scoring again [35]. However, IFAHP also has certain deficiency including dramatic increase in computational complexity due to the addition of the degree of nonmembership.

\subsection{Proposed Backfill Operation Models}

2.3.1. Self-Management Model. As shown in Figure 2, the first model is the self-management model [4]. For the selfmanagement model, the mine owner is committed to setting up a department of mine backfill, by which the activities of mine backfill are operated. Therefore, all of businesses involving mine backfill are controlled by the mine owner. The model requires that the mine owner enables to possess the backfill technology and expertise and provides enough financial support. The benefits and risks arising from backfill activities are held by the mine owner.

2.3.2. Outsourcing Model. As shown in Figure 2, the second model is the outsourcing model [4]. For the outsourcing model, the mine owner takes effort to select appropriate vendors or service providers as the operator employed for backfill operation service and management. Backfill vendors and backfill service providers are expected to provide physical resources, expertise, and sophisticated technology which are applied for mine backfill. According to classification of outsourcing engagement, there are four scopes of task outsourced including out-tasking, comanaged services, managed services, and full outsourcing [36]. However, there are certain possibilities that some risk might emerge such as cost escalation and inadequate performance of vendors [37].

2.3.3. Joint Venture Alliance. As shown in Figure 2, the third model is joint venture alliance [4]. For joint venture alliance, the mine owner is admitted to build an organizational alliance with the backfill vendor on the basis of institutional trust. The critical factors for the backfill vendor selected as the alliance partner are specialist knowledge, expertise, and professional equipment possessed by the vendor. All of the operational activities of backfill are controlled by joint venture alliance. Compared with the transaction relation, joint venture alliance is beneficial to reduce costs and time [38]. The mine owner and alliance partner share the rewards and risks according to the proportion of equity investment [39].

\section{Methodology}

It is crucial for the mining industry to select an appropriate backfill operation model. The flow chart of performance evaluation of the mine backfill operation model is shown in Figure 3. In the first step, the experts group is formed, in which the experts specialized in expertise and management knowledge of mine backfill are invited to participate in assessment of backfill operation models. In the second step, six perspectives of SBSC and performance indexes in terms of mine backfill are identified. In the third step, each expert in the group measures the importance degree of indexes and constructs the complementary matrix of IFPR. In addition, each expert is required to provide the evaluation matrix of three backfill operation models. In the fourth step, the intuitionistic fuzzy consistency judgment matrix is calculated, and the consistency test of the matrix is conducted by which the validity of the calculation result is determined. While the consistency test may fail, the parameter could be used to adjust until the consistency test is passed instead of scoring by experts again. In the fifth step, the weights of indexes and total weights are calculated. Subsequently, weighted results for each model are conducted, and final scores are obtained. Finally, the mine backfill operation models are summarized.

3.1. Identify SBSC Perspectives and Performance Indexes The SBSC method takes account of the sustainability issue. Some scholars insert sustainable indexes into the conceptual framework of BSC, while others incorporate eco-efficiency indexes into the BSC [40]. However, with green mining emphasized by more countries worldwide, this study prefers to address the environmental perspective and social perspective to the proposed SBSC evaluation framework. Therefore, there are six perspectives constructed for the performance measurement framework of the mine backfill including financial, stakeholders, internal process, learning and growth, and environmental and social perspective. As shown in Table 1, the performance indexes within the financial perspective are total capital input, operational cost optimization, and profit variance [24, 41, 42], whereas the stakeholders' perspective comprises indexes such as mine owner satisfaction, backfill vendor satisfaction, and regulatory satisfaction $[11,43,44]$. The internal process perspective involves mining-separation-backfill balance, flexibility, communication and collaboration efficiency $[3,45,46]$; whereas the learning and growth perspective comprises of training and development, technological innovation capability, and knowledge sharing [46-48]. The environmental perspective includes reduction of environmental impact and tailings utilization [45, 49]; the social perspective consists of employee accident and health of 


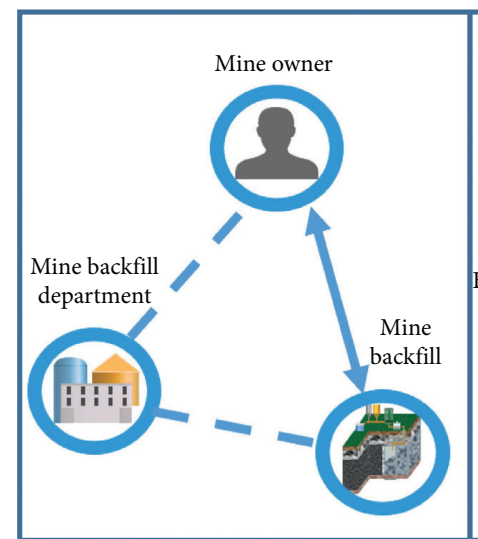

(a)

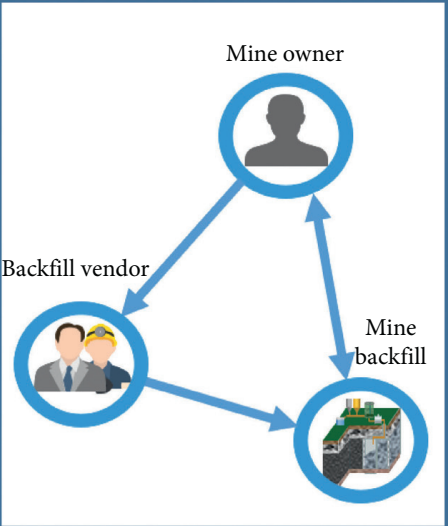

(b)

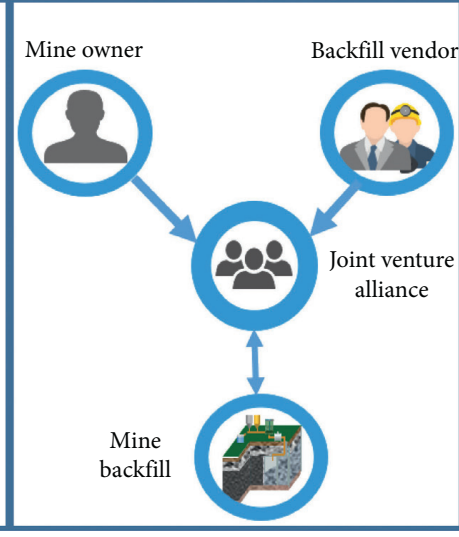

(c)

FIGURE 2: Schematic diagram of the proposed backfill operation models.

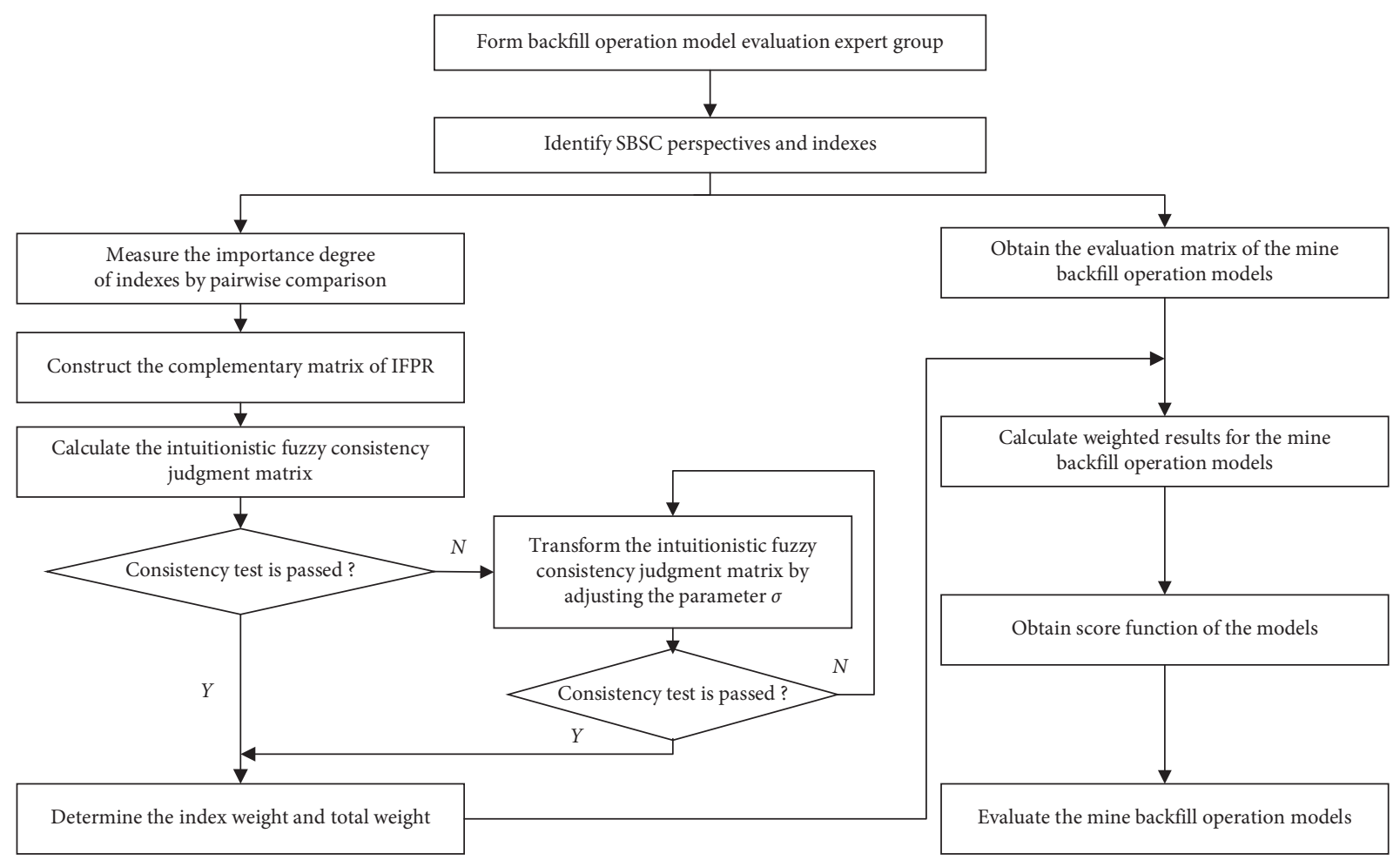

FIGURE 3: Flow chart of evaluation of mine backfill operation models.

residents $[49,50]$. The definitions and descriptions of the indexes are shown in Table 1.

\subsection{Steps of IFAHP}

3.2.1. Construction of the Complementary Matrix of IFPR Let a set of alternatives $C=\left\{c_{1}, c_{2}, \ldots, c_{n}\right\}$. The experts give the preference degree by comparing $c_{i}$ with $c_{j}$, $i, j=1,2, \ldots, n$. Generally, the experts need to provide the preference degree including the membership degree and nonmembership degree. However, it is very possible that experts feel hesitant to quickly give the degree of membership. Therefore, compared with the fuzzy preference relation, the intuitionistic fuzzy preference relation (IFPR) proposes the issue of the hesitation degree. IFPR on the set $C$ is represented by a complementary matrix $A=\left(r_{i j}\right)_{n \times n}$, where $r_{i j}=\left(\mu_{i j}, v_{i j}\right)$, and $\mu_{i j}$ is called the membership degree [35], and it indicates the degree to which $c_{i}$ is more important than $c_{j}$, and $v_{i j}$ is denoted as the nonmembership degree [35], and it represents the degree to which $c_{j}$ is more important than $c_{i}$. Both $\mu_{i j}$ and $v_{i j}$ are satisfied with the conditions including $\mu_{i j} \in[0,1], v_{i j} \in[0,1], 0 \leq \mu_{i j}+v_{i j} \leq 1$, and $\mu_{i j}=v_{j i}$. The hesitation degree or degree of uncertainty 
TABLE 1: Description of evaluation indexes.

\begin{tabular}{|c|c|c|}
\hline Evaluation indexes & Description & References \\
\hline \multicolumn{3}{|l|}{ Financial perspective (B1) } \\
\hline Total capital input $(\mathrm{C} 1)$ & $\begin{array}{l}\text { Investment related to mine backfill including equipment, } \\
\text { technology, professional technicians, and managers }\end{array}$ & Agrawal et al. [41] \\
\hline Operational cost optimization (C2) & $\begin{array}{c}\text { Optimization of expense items associated with operational } \\
\text { activities }\end{array}$ & Lee et al. [42] \\
\hline Profit variance $(\mathrm{C} 3)$ & Comparison of actual profit and planned profit & Epstein et al. [24] \\
\hline \multicolumn{3}{|l|}{ Stakeholders' perspective (B2) } \\
\hline Mine owner satisfaction (C4) & $\begin{array}{c}\text { Satisfaction degree of mine owner with financial and backfill } \\
\text { operational management }\end{array}$ & Lin et al. [43] \\
\hline Backfill vendor satisfaction (C5) & $\begin{array}{c}\text { Satisfaction degree of backfill vendor with financial and } \\
\text { empowerment }\end{array}$ & Moon et al. [11] \\
\hline Regulatory satisfaction (C6) & Compliance with standards and rules from regulatory bodies & Modak et al. [44] \\
\hline \multicolumn{3}{|l|}{ Internal process perspective (B3) } \\
\hline Mining-separation-backfill balance (C7) & $\begin{array}{l}\text { Mining, separation, and backfill process remain closed-loop } \\
\text { connection }\end{array}$ & Qi et al. [45] \\
\hline Flexibility (C8) & Ability to adapt to environmental and market changes & Baatartogtokh et al. [3] \\
\hline $\begin{array}{l}\text { Communication and collaboration } \\
\text { efficiency (C9) }\end{array}$ & $\begin{array}{l}\begin{array}{c}\text { Effectiveness of communication and collaboration among } \\
\text { stakeholders }\end{array} \\
\end{array}$ & Tsai et al. [46] \\
\hline \multicolumn{3}{|l|}{ Learning and growth perspective (B4) } \\
\hline Training and development (C10) & $\begin{array}{c}\text { Improvement of employee's capacity by training of expertise } \\
\text { and skill }\end{array}$ & Modak et al. [44] \\
\hline Technological innovation capability (C11) & Motivation and capacity to continuously improve technology & Khaleie et al. [48] \\
\hline Knowledge sharing $(\mathrm{C} 12)$ & $\begin{array}{c}\text { Sharing knowledge and information associated with backfill } \\
\text { activities among stakeholders }\end{array}$ & Tsai et al. [46] \\
\hline \multicolumn{3}{|l|}{ Environmental perspective (B5) } \\
\hline Tailings utilization (C13) & $\begin{array}{c}\text { Minimization of risk of environmental pollution through } \\
\text { implementing backfill technology }\end{array}$ & Liu et al. [49] \\
\hline Reduction of environmental impact (C14) & Percentage of tailings backfilled to underground voids & Qi et al. [45] \\
\hline \multicolumn{3}{|l|}{ Social perspective (B6) } \\
\hline Employee accident (C15) & Occupational accident rate of employee & Zhao et al. [50] \\
\hline Health of residents (C16) & Impact on community residents' health condition & Liu et al. [51] \\
\hline
\end{tabular}

$\pi_{i j}$ is calculated through $\pi_{i j}=1-\mu_{i j}-\nu_{i j}$. In order to quantify the degree of preference by pairwise comparison, the related evaluation scale is proposed by Atanassov [52], as shown in Table 2.

3.2.2. Consistency Test. The process of consistency test shows the improvement of IFAHP compared to the traditional AHP method, which reflects validity of the conclusion. Based on the complementary matrix of IFPR $A=\left(r_{i j}\right)_{n \times n}$, the matrix $\bar{A}=\left(\bar{r}_{i j}\right)_{n \times n}$ is obtained by the way of calculation, which is denoted as the intuitionistic fuzzy consistency judgment matrix.

$$
\text { When } j>i+1 \text {, then } \bar{r}_{i j}=\left(\bar{\mu}_{i j}, \bar{v}_{i j}\right)[53] \text {, }
$$

$$
\begin{aligned}
& \bar{\mu}_{i j}=\sqrt[j-i-1]{\frac{\prod_{t=i+1}^{j-1} \mu_{i t} \mu_{t j}}{\sqrt[j-i-1]{\prod_{t=i+1}^{j-1} \mu_{i t} \mu_{t j}+\sqrt[j-i-1]{\prod_{t=i+1}^{j-1}\left(1-\mu_{i t}\right)\left(1-\mu_{t j}\right), \quad j>i+1}}}} \\
& \bar{v}_{i j}=\sqrt[j-i-1]{\frac{\prod_{t=i+1}^{j-1} v_{i t} v_{t j}}{\sqrt[j-i-1]{\prod_{t=i+1}^{j-1} v_{i t} v_{t j}+\sqrt[j-i-1]{\prod_{t=i+1}^{j-1}\left(1-v_{i t}\right)\left(1-v_{t j}\right), \quad j>i+1}}}}
\end{aligned}
$$

When $j=i+1$, then $\bar{r}_{i j}=\left(\mu_{i j}, v_{i j}\right)$;

When $j<i$, then $\bar{r}_{i j}=\left(\bar{\nu}_{j i}, \bar{\mu}_{j i}\right)$.
The values of $\mu_{i j}, \bar{\mu}_{i j}, v_{i j}$, and $\bar{v}_{i j}$ are subsequently brought into the following formula for the consistency test [53]: 
TABLE 2: IFAHP pairwise comparison scale and meaning

\begin{tabular}{l}
\hline Meaning \\
$\begin{array}{l}\text { Compared with two factors, } i \text { is extremely better } \\
\text { than } j\end{array}$ \\
$\begin{array}{l}\text { Compared with two factors, } i \text { is strongly better } \\
\text { than } j\end{array}$ \\
$\begin{array}{l}\text { Compared with two factors, } i \text { is obviously better } \\
\text { than } j\end{array}$ \\
$\begin{array}{l}\text { Compared with two factors, } i \text { is slightly better } \\
\text { than } j\end{array}$ \\
$\begin{array}{l}\text { Compared with two factors, } i \text { is equivalent to } \\
j(i \neq j)\end{array}$ \\
$\begin{array}{l}\text { Compared with two factors, } j \text { is slightly better } \\
\text { than } i\end{array}$ \\
$\begin{array}{l}\text { Compared with two factors, } j \text { is obviously better } \\
\text { than } i\end{array}$ \\
$\begin{array}{l}\text { Compared with two factors, } j \text { is strongly better } \\
\text { than } i\end{array}$ \\
$\begin{array}{l}\text { Compared with two factors, } j \text { is extremely better } \\
\text { than } i\end{array}$ \\
\hline
\end{tabular}

$$
\begin{aligned}
d(\bar{A}, A)= & \frac{1}{2(n-1)(n-2)} \sum_{i=1}^{n} \sum_{j=1}^{n} \\
& \cdot\left(\left|\bar{\mu}_{i j}-\mu_{i j}\right|+\left|\bar{\nu}_{i j}-v_{i j}\right|+\left|\bar{\pi}_{i j}-\pi_{i j}\right|\right) .
\end{aligned}
$$

If $d(\bar{A}, A)<0.1$, it means $\bar{A}$ passed the consistency test.

If $d(\bar{A}, A) \geq 0.1$, it means $\bar{A}$ does not pass the consistency test. However, it is not indispensable that the experts provide the preference degree once again. The parameter $\sigma$ is set and used for iteration, where $\sigma \in[0,1]$. The parameter $\sigma$ is changed in steps of -0.01 from 1 through the iteration process; correspondingly, the intuitionistic fuzzy consistency judgment matrix is adjusted:

$$
\begin{aligned}
& \tilde{\mu}_{i j}=\frac{\left(\mu_{i j}\right)^{1-\sigma}\left(\bar{\mu}_{i j}\right)^{\sigma}}{\left(\mu_{i j}\right)^{1-\sigma}\left(\bar{\mu}_{i j}\right)^{\sigma}+\left(1-\mu_{i j}\right)^{1-\sigma}\left(1-\bar{\mu}_{i j}\right)^{\sigma}}, \quad i, j \in[1, n] \\
& \tilde{\nu}_{i j}=\frac{\left(\nu_{i j}\right)^{1-\sigma}\left(\bar{\nu}_{i j}\right)^{\sigma}}{\left(v_{i j}\right)^{1-\sigma}\left(\bar{\nu}_{i j}\right)^{\sigma}+\left(1-v_{i j}\right)^{1-\sigma}\left(1-\bar{v}_{i j}\right)^{\sigma}}, \quad i, j \in[1, n] .
\end{aligned}
$$

According to abovementioned two formulas, the values of $\widetilde{u}_{i j}$ and $\widetilde{v}_{i j}$ are calculated, and the adjusted intuitionistic fuzzy consistency judgment matrix $\widetilde{A}=\left(\widetilde{r_{i j}}\right)_{n \times n}$ is obtained, where $\widetilde{r}_{i j}=\left(\widetilde{u_{i j}}, \widetilde{v_{i j}}\right)$. While $\widetilde{A}$ and $A$ are brought to the following formula and the consistency test still fails, the adjusting process by the parameter is repeatedly conducted until the consistency test is passed:

$$
d(\bar{A}, A)=\frac{1}{2(n-1)(n-2)} \sum_{i=1}^{n} \sum_{j=1}^{n}\left(\left|\tilde{\mu}_{i j}-\mu_{i j}\right|+\left|\tilde{\nu}_{i j}-v_{i j}\right|+\left|\tilde{\pi}_{i j}-\pi_{i j}\right|\right) .
$$

3.2.3. Determination of Weights. The relative weight of each index is calculated by the following formula on the basis of the intuitionistic fuzzy consistency judgment matrix [53]:

$$
\omega_{i=}\left[\frac{\sum_{j=1}^{n} \bar{\mu}_{i j}}{\sum_{i=1}^{n} \sum_{j=1}^{n}\left(1-\bar{v}_{i j}\right)}, 1-\frac{\sum_{j=1}^{n}\left(1-\bar{\nu}_{i j}\right)}{\sum_{i=1}^{n} \sum_{j=1}^{n} \bar{\mu}_{i j}}\right] .
$$

The weight of each secondary index and the corresponding first-level index is aggregated and weighted in accordance with the algorithm of the intuitionistic fuzzy value, and the total weight is obtained. The following are related formulas [35]:

$$
\begin{aligned}
& \omega_{1} \otimes \omega_{2}=\left(\mu_{\omega 1} \mu_{\omega 2}, \nu_{\omega 1}+\nu_{\omega 2}-v_{\omega 1} \nu_{\omega 2}\right), \\
& \omega_{1} \otimes \omega_{2}=\left(\mu_{\omega 1}+\mu_{\omega 2}-\mu_{\omega 1} \mu_{\omega 2}, v_{\omega 1} \nu_{\omega 2}\right), \\
& \omega\left(C_{i}\right)=\omega_{B_{k}} \otimes \omega_{c_{i}}, k, i \in[1, n] .
\end{aligned}
$$

3.2.4. Calculation of Final Evaluation. The score function and ranking function are calculated through the following formulas based on the intuitionistic fuzzy value [53]. Generally, the higher the score function value, the better the evaluation of this backfill operation model. The higher the ranking function value, the lower the evaluation of this backfill operation model:

$$
\begin{aligned}
H(\omega) & =\frac{1-v_{i j}}{2-\mu_{i j}-v_{i j}}, \\
\rho(\omega) & =0.5\left(1+\pi_{\omega}\right)\left(1-\mu_{\omega}\right) .
\end{aligned}
$$

\section{Results and Discussion}

\subsection{Results}

4.1.1. Establishing the Complementary Matrix of IFPR There are ten experts in the panel with rich technology knowledge and management experience in the field of mine backfill in China. The experts are invited to provide their preference degree including IFPR of first-level indexes and IFPR of secondary indexes. Moreover, the membership degree and nonmembership degree given by ten experts 
need to be arithmetically averaged. So the complementary matrices of IFPR are determined:

$$
\begin{aligned}
& A=\left[\begin{array}{l}
(0.5,0.5)(0.570,0.265)(0.430,0.405)(0.510,0.305)(0.590,0.255)(0.640,0.230) \\
(0.265,0.570)(0.5,0.5)(0.380,0.480)(0.450,0.385)(0.520,0.290)(0.560,0.270) \\
(0.405,0.430)(0.480,0.380)(0.5,0.5)(0.550,0.275)(0.640,0.230)(0.670,0.215) \\
(0.305,0.510)(0.385,0.450)(0.275,0.550)(0.5,0.5)(0.580,0.260)(0.610,0.245) \\
(0.255,0.590)(0.290,0.520)(0.230,0.640)(0.260,0.580)(0.5,0.5)(0.530,0.285) \\
(0.230,0.640)(0.270,0.560)(0.215,0.670)(0.245,0.610)(0.285,0.530)(0.5,0.5)
\end{array}\right], \\
& A_{1}=\left[\begin{array}{l}
(0.5,0.5)(0.550,0.275)(0.560,0.270) \\
(0.275,0.550)(0.5,0.5)(0.510,0.305) \\
(0.270,0.560)(0.305,0.510)(0.5,0.5)
\end{array}\right] \text {, } \\
& A_{2}=\left[\begin{array}{l}
(0.5,0.5)(0.540,0.280)(0.560,0.270) \\
(0.280,0.540)(0.5,0.5)(0.500,0.330) \\
(0.270,0.560)(0.330,0.500)(0.5,0.5)
\end{array}\right] \text {, } \\
& A_{3}=\left[\begin{array}{l}
(0.5,0.5)(0.530,0.285)(0.520,0.290) \\
(0.285,0.530)(0.5,0.5)(0.500,0.310) \\
(0.290,0.520)(0.310,0.500)(0.5,0.5)
\end{array}\right] \text {, } \\
& A_{4}=\left[\begin{array}{l}
(0.5,0.5)(0.485,0.335)(0.500,0.320) \\
(0.305,0.510)(0.5,0.5)(0.530,0.285) \\
(0.295,0.530)(0.285,0.530)(0.5,0.5)
\end{array}\right], \\
& A_{5}=\left[\begin{array}{l}
(0.5,0.5)(0.560,0.270) \\
(0.270,0.560)(0.5,0.5)
\end{array}\right] \text {, } \\
& A_{6}=\left[\begin{array}{l}
(0.5,0.5)(0.590,0.255) \\
(0.255,0.590)(0.5,0.5)
\end{array}\right] \text {. }
\end{aligned}
$$

4.1.2. Consistency Test. The intuitionistic fuzzy consistency judgment matrix on first-level indexes $\bar{A}$ can be calculated by using equations (1) and (2):

$$
\bar{A}=\left[\begin{array}{c}
(0.5,0.5)(0.5700,0.2650)(0.4483,0.2497)(0.5000,0.1945)(0.5840,0.1427)(0.6178,0.1291) \\
(0.2650,0.5700)(0.5,0.5)(0.3800,0.4800)(0.4283,0.2593)(0.5260,0.1976)(0.5552,0.1687) \\
(0.2497,0.4483)(0.4800,0.3800)(0.5,0.5)(0.5500,0.2750)(0.6280,0.1176)(0.6619,0.1080) \\
(0.1945,0.5000)(0.2593,0.4283)(0.2750,0.5500)(0.5,0.5)(0.5800,0.2600)(0.6090,0.1228) \\
(0.1427,0.5840)(0.1976,0.5260)(0.1176,0.6280)(0.2600,0.5800)(0.5,0.5)(0.5300,0.2850) \\
(0.1291,0.6178)(0.1687,0.5552)(0.1080,0.6619)(0.1228,0.6090)(0.2850,0.5300)(0.5,0.5)
\end{array}\right] .
$$

Putting $A$ and $\bar{A}$ into equation (3), we get $d(\bar{A}, A)$ $=0.0625<0.1$, and it means $\bar{A}$ passes the consistency test. Similarly, the intuitionistic fuzzy consistency judgment matrix on secondary indexes $\bar{A}_{1}, \overline{A_{2}}, \overline{A_{3}}, \overline{A_{4}}, \overline{A_{5}}$, and $\bar{A}_{6}$ are brought to equations (1) and (2) for the consistency test. It is found that $d\left(\overline{A_{1}}, A_{1}\right)=0.0637<0.1, d\left(\overline{A_{2}}, A_{2}\right)=0.0646<0.1$, $d\left(\overline{A_{3}}, A_{3}\right)=0.0741<0.1, \quad d\left(\overline{A_{4}}, A_{4}\right)=0.0839<0.1, \quad d\left(\overline{A_{5}}, A_{5}\right)$ $=0<0.1$, and $d\left(\overline{A_{6}}, A_{6}\right)=0<0.1$, which demonstrate that the seven intuitionistic fuzzy consistency judgment matrices pass the consistency test at one time. 
4.1.3. Determining Weight. According to equation (7), the weights of six first-level indexes are obtained:

$$
\begin{aligned}
& \omega_{B 1}=(0.1590,0.8234), \\
& \omega_{B 2}=(0.1590,0.8234), \\
& \omega_{B 3}=(0.1593,0.8237), \\
& \omega_{B 4}=(0.1303,0.7859), \\
& \omega_{B 5}=(0.1013,0.7482), \\
& \omega_{B 6}=(0.0856,0.7277) .
\end{aligned}
$$

Similarly, the same method is used to bring the intuitionistic preference relation matrix of secondary indexes into equation (7). Then, the weight of each secondary index and its corresponding first-level index is aggregated by using equation (10); hence, the total weight integrated first-level index with the secondary index is obtained and shown in Table 3:

$$
\begin{aligned}
\omega\left(C_{j}\right) & =\omega_{B 1} \otimes \omega_{C 1}=(0.1590,0.8234) \otimes(0.3201,0.6499) \\
& =(0.0509,0.9382) .
\end{aligned}
$$

4.1.4. Evaluation of the Models. Ten experts are asked to rate the abovementioned backfill operation models on the IFAHP pairwise comparison scale. The arithmetic average of ten evaluation scores is taken as the expert evaluation result, by which the intuitionistic fuzzy evaluation matrix is constructed, as shown in Table 4. The evaluation results of the backfill operational models including $M 1, M 2$, and $M 3$ are calculated through using the algorithm for the intuitionistic fuzzy value including equations (8) and (9). The score function is calculated by applying equation (11). The ranking function is calculated by applying equation (12).

$$
\begin{aligned}
& M 1=\oplus_{i=1}^{16} \quad M_{1 j} \otimes \omega\left(C_{j}\right)=(0.41,0.48) \otimes \quad(0.0509, \\
& 0.9382) \oplus(0.56, \quad 0.33) \otimes \quad(0.0405, \quad 0.9237) \oplus \quad(0.57, \\
& 0.35) \otimes \quad(0.0340, \quad 0.9144) \oplus(0.72,0.21) \otimes \quad(0.0418, \\
& 0.9251) \oplus(0.57,0.29)(0.0335,0.9080) \oplus(0.67,0.25) \otimes \\
& (0.0288,0.8984) \oplus(0.66,0.26) \otimes(0.0487,0.9350) \oplus \\
& (0.57,0.32) \otimes(0.0404,0.9232) \oplus(0.59,0.32) \otimes(0.0346 \text {, } \\
& 0.9149) \oplus \quad(0.32, \quad 0.60) \otimes \quad(0.0388, \quad 0.9191) \oplus \quad(0.35 \text {, } \\
& 0.57) \otimes(0.0349, \quad 0.9111) \oplus(0.39,0.53) \otimes(0.0282, \\
& 0.8975) \oplus \quad(0.51, \quad 0.39) \otimes \quad(0.0495, \quad 0.8707) \oplus \quad(0.62, \\
& 0.31) \otimes(0.0359, \quad 0.8308) \oplus(0.64,0.29) \otimes(0.0433 \text {, } \\
& 0.8657) \oplus \quad(0.61, \quad 0.31) \otimes \quad(0.0300, \quad 0.8163) \\
& =(0.2882,0.3409) \\
& M 2=\oplus_{i=1}^{16}\left(M_{2 j} \otimes \omega\left(C_{j}\right)\right)=(0.3370,0.2859) \\
& M 3=\oplus_{i=1}^{16}\left(M_{3 j} \omega\left(C_{j}\right)\right)=(0.3394,0.2814) \\
& H(1)=0.4808, H(2)=0.5186 \text {, and } H(3)=0.5210 \\
& \rho(1)=0.4879, \rho(2)=0.4565 \text {, and } \rho(3)=0.4555
\end{aligned}
$$

4.2. Discussion. This study focuses on how to make decision on the optimal backfill operation model in the mining industries and proposes joint venture alliance. The score
TABLe 3: Weight of each index and total weight.

\begin{tabular}{lcc}
\hline First-level index & Secondary index & Total weight \\
\hline & C1 $(0.3201,0.6499)$ & $(0.0509,0.9382)$ \\
B1 $(0.1590,0.8234)$ & C2 $(0.2555,0.5680)$ & $(0.0405,0.9237)$ \\
& C3 $(0.2137,0.5151)$ & $(0.0340,0.9144)$ \\
\hline & C4 $(0.3187,0.6482)$ & $(0.0418,0.9251)$ \\
B2 $(0.1313,0.7872)$ & C5 $(0.2550,0.5678)$ & $(0.0335,0.9080)$ \\
& C6 $(0.2191,0.5226)$ & $(0.0288,0.8984)$ \\
\hline & C7 $(0.3060,0.6315)$ & $(0.0487,0.9350)$ \\
B3 $(0.1593,0.8237)$ & C8 $(0.2537,0.5642)$ & $(0.0404,0.9232)$ \\
& C9 $(0.2172,0.5172)$ & $(0.0346,0.9149)$ \\
\hline & C10 $(0.2976,0.6222)$ & $(0.0388,0.9191)$ \\
B4 (0.1303,0.7859) & C11 $(0.2675,0.5848)$ & $(0.0349,0.9111)$ \\
& C12 $(0.2164,0.5212)$ & $(0.0282,0.8975)$ \\
\hline \multirow{2}{*}{ B5 (0.1013,0.7482) } & C13 $(0.4885,0.4863)$ & $(0.0495,0.8707)$ \\
& C14 $(0.3548,0.3279)$ & $(0.0359,0.8308)$ \\
\hline \multirow{2}{*}{ B6 $(0.0856,0.7277)$} & C15 $(0.5058,0.5068)$ & $(0.0433,0.8657)$ \\
& C16 $(0.3503,0.3252)$ & $(0.0300,0.8163)$ \\
\hline
\end{tabular}

TABLE 4: Intuitionistic fuzzy evaluation matrix of the models.

\begin{tabular}{lcc}
\hline$M_{1 j}$ & $M_{2 j}$ & $M_{3 j}$ \\
\hline$(0.41,0.48)$ & $(0.62,0.28)$ & $(0.74,0.20)$ \\
$(0.56,0.33)$ & $(0.65,0.25)$ & $(0.71,0.21)$ \\
$(0.57,0.35)$ & $(0.69,0.22)$ & $(0.73,0.21)$ \\
$(0.72,0.21)$ & $(0.66,0.23)$ & $(0.74,0.20)$ \\
$(0.57,0.29)$ & $(0.69,0.21)$ & $(0.74,0.18)$ \\
$(0.67,0.25)$ & $(0.73,0.19)$ & $(0.71,0.20)$ \\
$(0.66,0.26)$ & $(0.69,0.23)$ & $(0.62,0.28)$ \\
$(0.57,0.32)$ & $(0.74,0.19)$ & $(0.61,0.26)$ \\
$(0.59,0.32)$ & $(0.69,0.22)$ & $(0.64,0.25)$ \\
$(0.32,0.60)$ & $(0.62,0.29)$ & $(0.58,0.32)$ \\
$(0.35,0.57)$ & $(0.44,0.50)$ & $(0.53,0.39)$ \\
$(0.39,0.53)$ & $(0.56,0.36)$ & $(0.58,0.33)$ \\
$(0.51,0.39)$ & $(0.69,0.23)$ & $(0.65,0.27)$ \\
$(0.62,0.31)$ & $(0.70,0.22)$ & $(0.66,0.23)$ \\
$(0.64,0.29)$ & $(0.71,0.22)$ & $(0.71,0.22)$ \\
$(0.61,0.31)$ & $(0.66,0.27)$ & $(0.69,0.22)$ \\
\hline
\end{tabular}

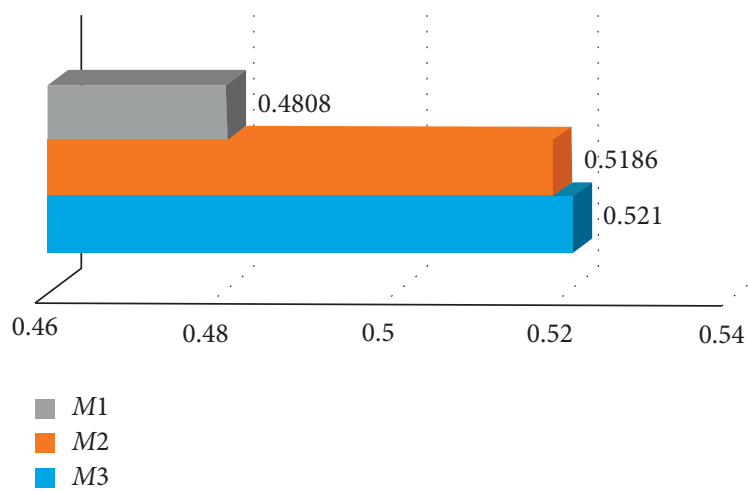

Figure 4: Comparison chart of the score function of the models.

functions of the models are clearly shown in Figure 4. As seen from the graph, the highest rating is joint venture alliance, with a score function of 0.5210 , which is viewed as 
TABLE 5: Score function of the secondary index on the three backfill operation models.

\begin{tabular}{|c|c|c|c|c|}
\hline Secondary index & Total weight & $M_{1 j}$ & $M_{2 j}$ & $M_{3 j}$ \\
\hline Total capital input (C1) & $(0.0509,0.9382)$ & 0.4685 & 0.6545 & 0.6822 \\
\hline Operational cost optimization $(\mathrm{C} 2)$ & $(0.0405,0.9237)$ & 0.6036 & 0.6818 & 0.7547 \\
\hline Profit variance $(\mathrm{C} 3)$ & $(0.0340,0.9144)$ & 0.6019 & 0.7156 & 0.7312 \\
\hline Mine owner satisfaction $(\mathrm{C} 4)$ & $(0.0418,0.9251)$ & 0.7383 & 0.6937 & 0.7453 \\
\hline Backfill vendor satisfaction (C5) & $(0.0335,0.9080)$ & 0.6228 & 0.7182 & 0.7547 \\
\hline Regulatory satisfaction (C6) & $(0.0288,0.8984)$ & 0.6944 & 0.7500 & 0.7593 \\
\hline Mining-separation-backfill balance (C7) & $(0.0487,0.9350)$ & 0.6852 & 0.7130 & 0.7340 \\
\hline Flexibility (C8) & $(0.0404,0.9232)$ & 0.6126 & 0.7570 & 0.6546 \\
\hline Communication and collaboration efficiency (C9) & $(0.0346,0.9149)$ & 0.6239 & 0.7156 & 0.6549 \\
\hline Training and development (C10) & $(0.0388,0.9191)$ & 0.3704 & 0.6514 & 0.6757 \\
\hline Technological innovation capability (C11) & $(0.0349,0.9111)$ & 0.3981 & 0.4717 & 0.6182 \\
\hline Knowledge sharing (C12) & $(0.0282,0.8975)$ & 0.4352 & 0.5926 & 0.5648 \\
\hline Tailings utilization (C13) & $(0.0495,0.8707)$ & 0.5545 & 0.7130 & 0.6147 \\
\hline Reduction of environmental impact (C14) & $(0.0359,0.8308)$ & 0.6449 & 0.7222 & 0.6759 \\
\hline Employee accident (C15) & $(0.0433,0.8657)$ & 0.6636 & 0.7290 & 0.6937 \\
\hline Health of residents $(\mathrm{C} 16)$ & $(0.0300,0.8163)$ & 0.6389 & 0.6822 & 0.7290 \\
\hline Final score & & 0.4808 & 0.5186 & 0.5210 \\
\hline
\end{tabular}

the optimal strategic operation mechanism for mine backfill in the study. The next to be followed closely is the outsourcing model, which has a score function of 0.5186 . However, compared with other models, the self-management model receives a lower score function of 0.4808 , and this implies that the outsourcing model is suboptimal decision-making whereas the self-management model has fewer advantages.

The intuitive fuzzy evaluation matrix is transformed into the score function by using equation (11), as seen in Table 5 . There are 16 secondary indexes constructed under 6 perspectives, among which the financial perspective covers 3 criteria including total capital input, operational cost optimization, and profit variance, and the top importance of these indexes for evaluating the backfill operation business is given to joint venture alliance with scores of $0.6822,0.7547$, and 0.7312 . This indicates that joint venture alliance has the advantages in reducing investment cost, optimizing cost structure, and profitability, which is followed by the outsourcing model. For the stakeholders' perspective, there are three secondary indexes under the first-level index, which are mine owner satisfaction, backfill vendor satisfaction, and regulatory satisfaction. Similarly, in the models, joint venture alliance receives the highest importance of 0.7453 , 0.7547 , and 0.7593 . This manifests mine owners and ventures as well as regulators who have high satisfaction with joint venture alliance. The internal process perspective covers three secondary indexes, in which the highest score of mining-separation-backfill balance is given to the joint venture alliance whereas the outsourcing model receives the top importance of flexibility, communication and collaboration efficiency. It shows the superiority of the outsourcing model over other models in adaptability and communication capability. The fourth perspective, learning and growth, includes three secondary indexes, and joint venture alliance is rated as the top importance with regard to training and development and technological innovation capability whereas the outsourcing model is considered the highest importance with respect to knowledge sharing. It demonstrates that joint venture alliance has a greater impact on employee learning and technical improvement of the mining industry. For the environmental perspective, the outsourcing model receives the top score about tailings utilization and reduction of environmental impact, which implies that the model helps promote environmental protection. For the social perspective, joint venture alliance is rated as the top importance in regard to employee accident and health of residents, which shows that this model plays the significant role in fulfilling corporate social responsibility. In summary, joint venture alliance has greater advantages than the self-management and outsourcing model.

\section{Conclusion}

It is indispensable for the mining industry to find an appropriate backfill operational mechanism which will facilitate the development of the mine backfill business; therefore, this study proposes joint venture alliance; on this basis, the model is compared with the self-management and outsourcing model by the way of the integrated methods. In order to assess three operation models, the study puts forward the hierarchical framework and evaluation system of mine backfill business evaluation, and the IFAHP method is used to estimate the optimal model. It is found to draw the following conclusions through adopting the proposed approach.

(1) This study establishes a strategic and hierarchical framework for evaluating the backfill operation model in the mining industry, which fully takes into account sustainability and includes 6 perspectives and 16 secondary indexes. In addition to financial, stakeholders, internal process, and learning and growth perspectives, environmental and social perspectives are integrated into the framework.

(2) Considering the hesitant degree existing under the fuzzy environment and the fuzzy mathematical thought, this study proposes the IFAHP approach, 
which is applied to determine the relative weight of each index and total weight and calculate the final score. Due to superiority of the IFAHP approach, this method enables to reveal objectivity in the process of model evaluation. Therefore, the integrated method is addressed through applying SBSC along with the IFAHP approach, which better shows the combination of several factors concerned including strategy, sustainability, hierarchy, and objectivity.

(3) There are self-management and outsourcing generally used as backfill operation models worldwide, whose advantages are insufficient from the strategic and sustainability perspective. The novelty of this study lies in proposing joint venture alliance and exploring its superiority in the mine backfill management. Through comparison and evaluation of the models including joint venture alliance, self-management, and outsourcing, the results show that joint venture alliance receives the top score, next is followed by the outsourcing model, and the last one is the self-management model. Thus, joint venture alliance is considered as the optimal operation mechanism of the mine backfill, followed by the outsourcing model, and the self-management model has few advantages compared with the other models.

\section{Data Availability}

All data are valid and included within this paper.

\section{Conflicts of Interest}

The authors declare that they have no conflicts of interest.

\section{Acknowledgments}

This research was supported by the National Natural Science Foundation of China (nos. 51874229, 51904224, 51904225, and 52004207).

\section{References}

[1] A. Gunasekaran, Z. Irani, K.-L. Choy, L. Filippi, and T. Papadopoulos, "Performance measures and metrics in outsourcing decisions: a review for research and applications," International Journal of Production Economics, vol. 161, pp. 153-166, 2015.

[2] ICC, Coal Mining Is Private Participation the Answer?, Indian Chamber of Commerce, Kolkata, India, 2013.

[3] B. Baatartogtokh, W. S. Dunbar, and D. Van Zyl, "The state of outsourcing in the Canadian mining industry," Resources Policy, vol. 59, pp. 184-191, 2018.

[4] R. Sivakumar, D. Kannan, and P. Murugesan, "Green vendor evaluation and selection using AHP and Taguchi loss functions in production outsourcing in mining industry," Resources Policy, vol. 46, pp. 64-75, 2015.

[5] NCL, "Northern coalfields limited," Annual Report 2014-15, NCL, Madhya Pradesh, India, 2015.

[6] SECL, "Himalaya granites limited," 29th Annual Report 201415, South Eastern Coalfields Limited, Chattisgarh, India, 2015.
[7] F. Nan, Y. Chen, H. Feng, D. Li, and M. Li, "To outsource or not: the impact of information leakage risk on information security strategy," Information \&Management, vol. 57, Article ID 103215, 2020.

[8] T. K. Das and B.-S. Teng, "Instabilities of strategic alliances: an internal tensions perspective," Organization Science, vol. 11, no. 1, pp. 77-101, 2000.

[9] J. Y. Murray and M. Kotabe, "Performance implications of strategic fit between alliance attributes and alliance forms," Journal of Business Research, vol. 58, no. 11, pp. 1525-1533, 2005.

[10] V. Durmaz and L. Zheng, "The effect of joint ventures on airline competition: the case of American airlines, British airways and iberia joint business," Procedia-Social and Behavioral Sciences, vol. 210, pp. 430-439, 2015.

[11] Y. Moon, T. Yao, and B. Jiang, "Outsourcing versus joint venture from vendor's perspective," International Journal of Production Economics, vol. 129, no. 1, pp. 23-31, 2011.

[12] O. Demirtas, "Evaluating the core capabilities for strategic outsourcing decisions at aviation maintenance industry," Procedia - Social and Behavioral Sciences, vol. 99, pp. 11341143, 2013.

[13] Y. Tjader, J. H. May, J. Shang, L. G. Vargas, and N. Gao, "Firm-level outsourcing decision making: a balanced scorecard-based analytic network process model," International Journal of Production Economics, vol. 147, pp. 614-623, 2014.

[14] A. Makan and F. Ahmed, "Sustainability assessment of largescale composting technologies using Promethee method," Journal of Cleaner Production, vol. 261, Article ID 121244, 2020.

[15] H.-Y. Wu, "Constructing a strategy map for banking institutions with key performance indicators of the balanced scorecard," Evaluation and Program Planning, vol. 35, no. 3, pp. 303-320, 2012.

[16] G. Ozkaya and C. Erdin, "Evaluation of smart and sustainable cities through a hybrid MCDM approach based on ANP and TOPSIS technique," Heliyon, vol. 6, Article ID e05052, 2020.

[17] R. Davoudabadi, S. M. Mousavi, and V. Mohagheghi, "A new decision model based on DEA and simulation to evaluate renewable energy projects under interval-valued intuitionistic fuzzy uncertainty," Renewable Energy, vol. 164, pp. 1588-1601, 2020.

[18] C. Tian, J.-J. Peng, S. Zhang, J.-Q. Wang, and M. Goh, “A sustainability evaluation framework for WET-PPP projects based on a picture fuzzy similarity-based VIKOR method," Journal of Cleaner Production, vol. 289, Article ID 125130, 2020.

[19] M. Tavana, M. Zareinejad, D. Di Caprio, and M. A. Kaviani, "An integrated intuitionistic fuzzy AHP and SWOT method for outsourcing reverse logistics," Applied Soft Computing, vol. 40, pp. 544-557, 2016.

[20] M. Çolak and İ. Kaya, "Prioritization of renewable energy alternatives by using an integrated fuzzy MCDM model: a real case application for Turkey," Renewable and Sustainable Energy Reviews, vol. 80, pp. 840-853, 2017.

[21] Y. Xue, Y. Deng, and H. Garg, "Uncertain database retrieval with measure - based belief function attribute values under intuitionistic fuzzy set," Information Sciences, vol. 546, pp. 436-447, 2021.

[22] H. Garg, Z. Ali, and T. Mahmood, "Algorithms for complex interval-valued $q$-rung orthopair fuzzy sets in decision making based on aggregation operators,AHP,andTOPSIS," Expert Systems, vol. 38, no. 1, 2021. 
[23] J. Puri, S. P. Yadav, and H. Garg, "A new multi-component DEA approach using common set of weights methodology and imprecise data: an application to public sector banks in India with undesirable and shared resources," Annals of Operations Research, vol. 259, no. 1-2, pp. 351-388, 2017.

[24] M. J. Epstein and P. S. Wisner, "Using a balanced scorecard to implement sustainability," Environmental Quality Management, vol. 11, no. 2, pp. 1-10, 2001.

[25] R. S. Kaplan and D. P. Norton, "The balanced scorecard: measures that drive performance," Harvard Business Review, vol. 70, pp. 71-99, 1992.

[26] F. Frank, T. Hahn, and S. Schaltegger, "The sustainability balanced scorecard-linking sustainability management to business strategy," Business Strategy and the Environment, vol. 11, pp. 269-284, 2002.

[27] M. Sidiropoulos, Y. Mouzakitis, E. Adamides, and S. Goutsos, "Applying sustainable indicators to corporate strategy: the eco-balanced scorecard," Environmental Research, Engineering Management, vol. 1, pp. 28-33, 2004.

[28] A. Möller and S. Schaltegger, "The sustainability balanced scorecard as a framework for eco-efficiency analysis," Journal of Industrial Ecology, vol. 9, no. 4, pp. 73-83, 2005.

[29] H. Graham, "Measuring organizational performance: beyond the triple bottom line," Business Strategy and the Environment, vol. 18, pp. 177-191, 2009.

[30] T. A. Tsalis, I. E. Nikolaou, E. Grigoroudis, and K. P. Tsagarakis, “A framework development to evaluate the needs of SMEs in order to adopt a sustainability-balanced scorecard," Journal of Integrative Environmental Sciences, vol. 10, pp. 3-4, 2013.

[31] I. Dias-Sardinha, L. Reijnders, and P. Antunes, "From environmental performance evaluation to eco-efficiency and sustainability balanced scorecards," Environmental Quality Management, vol. 12, no. 2, pp. 51-64, 2002.

[32] M. Radu, "Empirical study on the indicators of sustainable performance-the sustainability balanced scorecard, effect of strategic organizational change," Amfiteatru Economic, vol. 32, pp. 451-469, 2012.

[33] T. L. Saaty, The Analytic Hierarchy Process, McGraw-Hill, New York, NY, USA, 1980.

[34] H. Liao, Z. Xu, and X.-J. Zeng, "Distance and similarity measures for hesitant fuzzy linguistic term sets and their application in multi-criteria decision making," Information Sciences, vol. 271, pp. 125-142, 2014.

[35] H. Liao and Z. Xu, "Consistency of the fused intuitionistic fuzzy preference relation in group intuitionistic fuzzy analytic hierarchy process," Applied Soft Computing, vol. 35, pp. 812-826, 2015.

[36] R. Nada, "A multidimensional framework for understanding outsourcing arrangement," Journal of Supply Chain Management, vol. 43, pp. 3-15, 2007.

[37] C. Samantra, S. Datta, and S. S. Mahapatra, "Risk assessment in IT outsourcing using fuzzy decision-making approach: an Indian perspective," Expert Systems with Applications, vol. 41, no. 8, pp. 4010-4022, 2014.

[38] D. N. Burton, D. W. Dobler, and S. L. Starling, World Class Supply Management-The Key to Supply Chain Management, McGraw-Hill, New York, NY, USA, 7th edition, 2003.

[39] L. Cacciolatti, A. Rosli, J. L. Ruiz-Alba, J. Chang, and J. Chang, "Strategic alliances and firm performance in startups with a social mission," Journal of Business Research, vol. 106, pp. 106-117, 2020.

[40] M.-T. Lu, C.-C. Hsu, J. J. H. Liou, H.-W. Lo, and H.-W. Lo, “A hybrid MCDM and sustainability-balanced scorecard model to establish sustainable performance evaluation for international airports," Journal of Air Transport Management, vol. 71, pp. 9-19, 2018.

[41] S. Agrawal, R. K. Singh, and Q. Murtaza, "Outsourcing decisions in reverse logistics: sustainable balanced scorecard and graph theoretic approach," Resources, Conservation and Recycling, vol. 108, pp. 41-53, 2016.

[42] A. H. I. Lee, H.-Y. Kang, C.-F. Hsu, and H.-C. Hung, "A green supplier selection model for high-tech industry," Expert Systems with Applications, vol. 36, no. 4, pp. 7917-7927, 2009.

[43] X. Lin and C. L. Wang, "Enforcement and performance: the role of ownership, legalism and trust in international joint ventures," Journal of World Business, vol. 43, no. 3, pp. 340-351, 2008.

[44] M. Modak, K. Pathak, and K. K. Ghosh, "Performance evaluation of outsourcing decision using a BSC and Fuzzy AHP approach: a case of the Indian coal mining organization," Resources Policy, vol. 52, pp. 181-191, 2017.

[45] C. Qi and A. Fourie, "Cemented paste backfill for mineral tailings management: review and future perspectives," Minerals Engineering, vol. 144, Article ID 106025, 2019.

[46] F. M. Tsai, M.-L. Tseng, M. Lim, and K.-J. Wu, “Assessing a hierarchical sustainable solid waste management structure with qualitative information: policy and regulations drive social impacts and stakeholder participation," Resources, Conservation and Recycling, vol. 168, Article ID 119740, 2021.

[47] M. Modak, K. K. Ghosh, and K. Pathak, "A BSC-ANP approach to organizational outsourcing decision support-A case study," Journal of Business Research, vol. 103, pp. 432-447, 2019.

[48] S. Khaleie, M. Fasanghari, and E. Tavassoli, "Supplier selection using a novel intuitionist fuzzy clustering approach," Applied Soft Computing, vol. 12, no. 6, pp. 1741-1754, 2012.

[49] L. Liu, P. Yang, C. Qi, B. Zhang, L. Guo, and K.-I. Song, "An experimental study on the early-age hydration kinetics of cemented paste backfill," Construction and Building Materials, vol. 212, pp. 283-294, 2019.

[50] H. Zhao and N. Li, "Evaluating the performance of thermal power enterprises using sustainability balanced scorecard, fuzzy Delphic and hybrid multi-criteria decision making approaches for sustainability," Journal of Cleaner Production, vol. 108, pp. 569-582, 2015.

[51] L. Liu, Z. Fang, C. Qi, B. Zhang, L. Guo, and K.-I. Song, "Experimental investigation on the relationship between pore characteristics and unconfined compressive strength of cemented paste backfill," Construction and Building Materials, vol. 179, pp. 254-264, 2018.

[52] K. T. Atanassov, "More on intuitionistic fuzzy sets," Fuzzy Sets and Systems, vol. 33, no. 1, pp. 37-45, 1989.

[53] Z. Xu, "Intuitionistic preference relations and their application in group decision making," Information Sciences, vol. 177, no. 11, pp. 2363-2379, 2007. 